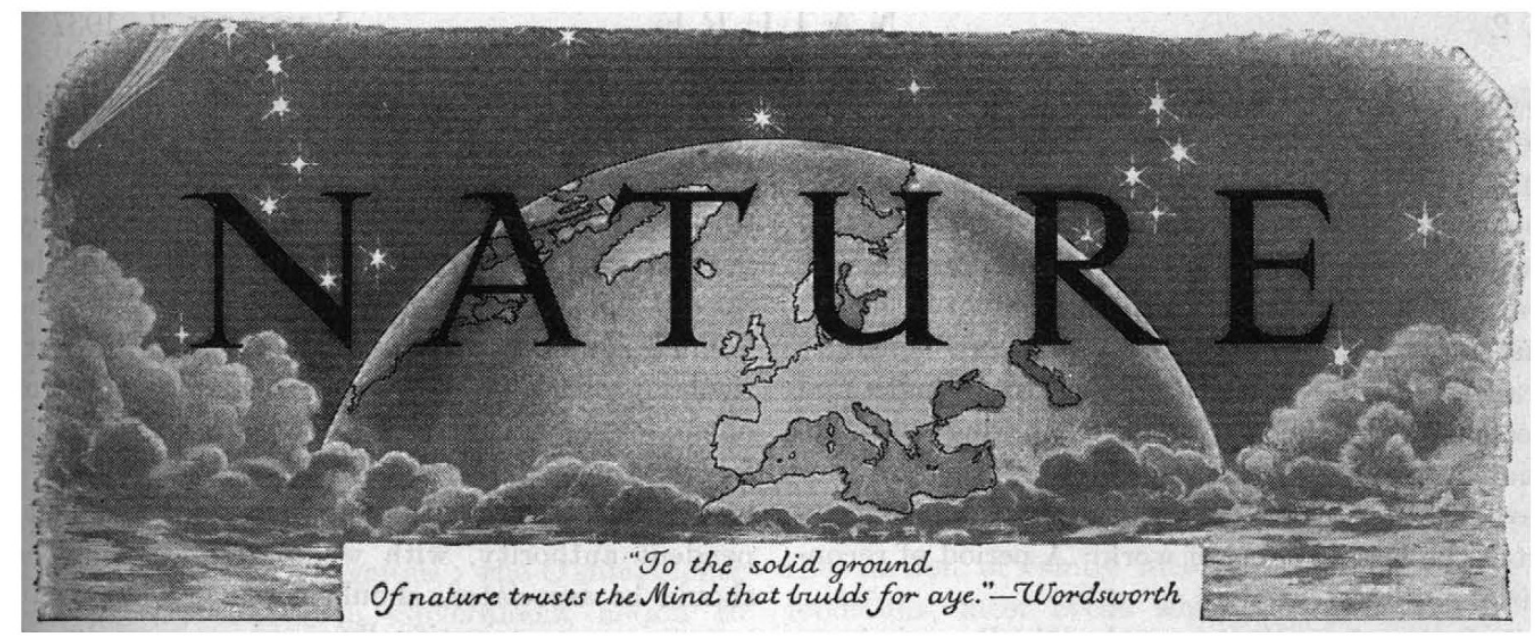

\title{
The Social Opportunity in the Special Areas
}

$\mathrm{I}^{\mathrm{N}}$ his presidential address to the British Association at Blackpool, Sir Josiah Stamp pointed out that society and its institutions should now be learning that change is a continuous function, and that meeting it requires the development of an appropriate technique. This passage in which Sir Josiah pleads for the development of social shock absorbers and accommodating mechanisms to assist in the transition and to minimize the disturbances to social relations and institutions arising from the application of scientific discoveries, is immediately recalled by the third report* of the Commissioner for the Special Areas (England and Wales), which has now been presented to Parliament.

The Chancellor of the Exchequer, when introducing the Special Areas Bill to the House of Commons, aptly described it as an experimentand, we may add, in view of the recent gift by Lord Nuffield of $£ 2,000,000$ to form a trust the activities of which will supplement the action of the State, an experiment which begins in the happiest circumstances. The Act may in fact be interpreted as an endeavour to determine the value to the Special Areas of providing special treatment, and to ascertain whether the results thereby obtained warrant a wide application. As such, it may indeed be regarded as an example of the machinery of social change and adaptation which Sir Josiah Stamp had in mind. Third Report of the Commissioner for the Special Areas (England
and Wales). (Cmd. 5303.) Pp. xil +210. (London: H.M. Stationery Office, 1936.) 3s. 6d. net.
In the present report, the Commissioner reviews the progress made since December 31, 1935, in the economic development and social improvement of the Special Areas. In many directions good progress has been made. An auspicious start has been made with trading estate companies for the north-east coast and for South Wales, and their activities should be favoured by the operations of the recently formed Special Areas Reconstruction Association. Evidence that financial assistance is required for small industrialists in the Areas is increasing, and the Commissioner considers that if the objectives of his recommendations are to be attained, somewhat greater risks must be taken in granting loans than are usually accepted by bankers and financial houses.

The formation of trading estates marks a direct and practical effort to attract industry, especially the lighter industries, to the Special Areas. Their expansion is essential to secure a better balanced industrial production, and the Commissioner reiterates the view expressed in his first report. He urges that efforts to attract such industries to the Areas should not be diminished on account of the prospective improvement arising from the defence programme on which Great Britain is now embarked. It is hoped that trading estates will become centres from which increased industrial activities will radiate.

Of specific works initiated, the most important is the construction of the deep-water quays near Jarrow, but the Land Settlement Association, the 
Welsh Land Settlement Society and the Durham County Council are steadily progressing and the early results of these experiments in land settlement are regarded as satisfactory. They have demonstrated the adaptability and keenness of the settlers, whose general improvement in health and physique is remarkable. It is not generally realized how far below the standard strength and health of the ordinary active working man are those who have been long out of work, and how severely they suffer both physically and mentally from the loss of habit of work. A period of reconditioning is essential.

It is clear from the report that the Commissioner is far from satisfied with the results so far achieved, even if no more could be done with his comparatively limited powers. He repeats the criticism and recommendations of his first report, and especially stresses the importance of the Severn Bridge scheme as a gateway to South Wales, for which he was unable to make a grant. Similarly, to open up western Cumberland for industrial development and tourist traffic, he recommends the improvement of communications from the south and the construction of an arterial road, involving the construction of a bridge across the Duddon estuary. Improved communications between the north and south bank of the Tyne, east of Newcastle, are also recommended, as well as the institution of steps to prevent Maryport harbour from becoming closed and derelict.

Other specific recommendations in this field which have strong claims for State support are the erection of plants for the production of oil from coal in the Special Areas, the installation of a factory in South Wales for the manufacture of calcium carbide, and encouragement of the use of Welsh smokeless coal for domestic purposes. In the same category falls the proposal for the establishmeut and development on modern lines of a national park in South Wales. The development of the production of oil from coal in the Special Areas is recommended in the interests of national defence, and on the same grounds the Commissioner directs attention to the advantages of relative safety offered by some districts in South Wales and Cumberland in regard to the decentralization of the production of aircraft. For the same reason attention is directed to the value of South Wales, and West Cumberland as sites for the storage of grain and of oil.

The development and attraction of industry, however, is only one of the two main methods envisaged by the Commissioner for dealing with the problem of unemployment within these areas. Equal stress is laid upon the adoption of measures to decrease unemployment generally, thereby making easier a reduction of its intensity in the Special Areas. In dealing with this question the Commissioner again refuses to dissociate the particular problem of the Special Areas from that of unemployment generally. The effects of transference are being increasingly felt, and he reiterates his recommendation that an impartial and independent authority, with whom the trade unions should be associated, should conduct a survey to ascertain as scientifically and accurately as possible what are the relative prospects of indus. trial revival in the different districts of the Special Areas. Transference should be concentrated on these districts which obviously offer the least prospect of recovery.

Once again the Commissioner emphasizes the seriousness of the position in regard to unemployment among young persons. Pointing out that more than two thirds of the young men who were interviewed refused training at a Government constructional centre or failed to attend after acceptance, he reluctantly concludes that too large a number of young men in the Special Areas are content to live in idleness as State pensioners and are unwilling to make any effort to find work. The danger involved both to the young men themselves and to society as a whole leads the Commissioner to recommend, first that the proportion of men from the Special Areas who satisfactorily complete a course of training at the Ministry of Labour instructional centre should be greatly increased, and secondly, that such attendance on the part of yourg men from the Special Areas should no longer be on a voluntary basis but be subject to an approved measure of compulsion.

The scientific worker will be disappointed at finding among these specific recommendations no further reference to those suggestions regarding the application of science to industry which are being considered by the North East Development Board, although following the survey of the industrial facilities of the north-east coast published in April last, a technical advisory committee has been set up to provide for the further exploration of the economic potentialities of the Area. On the other hand, the further discussion of general principles contained in Part 1 of the report raises questions with which scientific 
workers are directly concerned. The very fact that the Commissioner, in restating principles previously outlined, finds it necessary to regret that they had not been recognized as a logical conclusion in debating his first report, indicates the need for closer attention to these questions.

As a means of increasing industrial activity in the areas, persuasion has definite limits and in fact is regarded as a failure by the Commissioner. On the other hand, compulsory location is regarded as unnecessary and dangerous ; the Commissioner finds an alternative in Government action to prohibit the location of industry in particular areas unless good cause can be shown. His first recommendation is in fact that the further expansion of industry in Greater London should be controlled to secure a more evenly distributed production in which it is hoped the Special Areas would share.

The dangers attending the enormous post-War growth of Greater London, particularly in regard to adequate protection of food supplies in the event of a hostile attack, are cited in support of the Commissioner's argument that Government restraint on the further expansion of industry in the London area would indirectly benefit the Special Areas, and he refers to opportunities of exercising constraint at present available in the execution of the defence programme.

The Commissioner's recommendations involve the adoption of a definite plan to reduce unemployment in the Special Areas. He urges that if the Areas are to be given a reasonable chance of rehabilitation, industry must be attracted to them; to start the movement the initial effort must be powerful. Moreover, although, as he repeatedly points out, the problems of the Special Areas cannot be dealt with entirely apart from the general problems and well-being of the nation, we must not be afraid of making a break with the traditions and practices of the past. The application of unconventional principles may well be called for, particularly in respect of preferential treatment, and the Commissioner's suggestion that the possibility of removing from the live register those who have been out of work for more than five years and are never likely again to obtain employment should be considered, deserves serious attention.

Once again, in fact, Mr. Stewart has made it apparent how closely this problem is linked up with that of rearmament, of health, education and industrial and social development generally. He firmly dismisses the idea that the defence programme offers any solution, and in fact directs attention to the dangers of armaments activity in the Special Areas if other measures are not simultaneously applied. Similarly, he directs attention to the dangers to health which are inherent in the conditions of the Special Areas, and his proposals for physical exercise and training as well as for instruction on relative food values, simple cooking and on the best way to distribute the portion of family income which is spent on foodstuffs, meet needs which are probably only more intense in the Special Areas but equally to be found elsewhere.

The scientific worker cannot but be impressed with the opportunity which many of the Commissioner's recommendations afford of gaining experience as to the value of numerous suggestions for social development which may well have a wide application if their efficiency is once proved. Action in this direction should not be thwarted by the opposition of vested interests, as is alleged by the Commissioner in regard to at least one of his earlier proposals repeated in the present report, and the attention which the report has already aroused in Parliament indicates that strong support for many of its recommendations should be fortheoming.

Undoubtedly the Commissioner's view of the position in the Special Areas is much less optimistic than that taken by Government spokesmen, and he is most emphatic on the need for definite action in accordance with widely developed and longrange plans. None the less, even when due account is taken of some tragedies of the Special Areas in regard to juvenile unemployment and disintegration of morale, the dominant impression created by the report is that of opportunity and hope. The task of rehabilitating and transforming these Areas and slowly reintegrating them into the national life is not insoluble. It makes big demands on vision and resourcefulness in planning, in research, and in redistribution of material sources and effort. Given the will and a vision of the social possibilities, success is assured, and the experiments may well prove of even greater value in the adaptation of national life as a whole to changed conditions. For this reason alone, apart from their incidental contribution in specific technical questions, the latest survey of the Special Areas claims the close attention of scientific workers as of other members of the community. 